\title{
Comparative Study between Fixed Dose of Hyperbaric Bupivacaine and Dose Related to Height Used in Spinal Anesthesia for Caesarean Section in Normal and Pre- Eclamptic Patients
}

S.I.Saad, E.S.Afifi, M.F.El Meligy, D.H.Abd El Hameed and N.S.Amer

Anesthesia and ICU Dept., Faculty of Medicine, Benha Univ., Benha, Egypt

E-Mail: N.Amer@gmail.com

\begin{abstract}
Neuroaxial anesthesia has long been accepted as the standard practice for providing the safest anesthesia for cesarean section. Spinal anesthesia for CS should ideally last the duration of the procedure without producing maternal or fetal adverse effects. This study is to monitor the two techniques during cesarean section, fixed dose of bupivacaine not tailored to patient height and variable dose of bupivacaine tailored to patient height. We will compare the outcomes from the two different techniques regarding the level of anesthesia achieved, resulting hemodynamics (BP \& HR) ,the requirements for fluids \& pressors, development of nausea \& vomiting and the time needed to discharge from PACU. This study was conducted on 80 patients aged between 20 and 40 years old, ASA grade I and II . All patients were scheduled for elective cesarean section surgery. All cases were done in Benha university Hospitals after approved consent from the patients. The duration of sensory and motor block was significantly prolonged in fixed dose groups $(A \& C)$ than in adjusted dose groups (B\&D).The amount of fluids and vasopressors needed were significantly much more in fixed dose groups (A\&C) than in adjusted dose groups (B\&D). The incidence of complications (hypotension , nausea and vomiting) were significantly higher in fixed dose groups (A\&C) than in adjusted dose groups (B\&D). we have shown that adjusting the dose of hyperbaric bupivacine $(0.5 \%)$ according to height in both normal and preeclamptic patients, in combination with opioids (fentanyl $20 \mathrm{mcq}$ ), provide adequate anesthesia for elective cesarean section in both normal and pre-eclamptic patients. This regimen associated with decrease in cephalic spread of anesthesia, decrease incidence and severity of maternal hypotention ,nausea, vomiting, decrease the amount of fluids needed and the dosage of vasopressors used.
\end{abstract}

Keywords: Analgesia, Anesthesia, CS, AV, Hyperbaric bupivacine (0.5\%) and Pre-eclamptic patients.

\section{Introduction}

Neuroaxial anesthesia has long been accepted as The standard act for giving work to those most secure anesthesia to cesarean area (CS) [1].

Spinal anesthesia to cs if ideally keep going the span of the methodology without transforming maternal alternately fetal unfriendly impacts. As a general rule, finding a spinal method for cs that gives An dependable square without causing unfriendly impacts keeps on being a test in the field about obstetric anesthesia[2].

Those mossycup oak as a relatable point side impacts coming about because of spinal anesthesia to cs is hypotension for a news person frequency of $20 \%$ $100 \%$ over crisis cs. Often patients will experience a noteworthy sum from claiming queasiness Concerning illustration an aftereffect of this drop in pulse [3].

Anesthesia prompted maternal hypotension could likewise disable utero-placental perfusion What's more camwood prompt fetal academia[4].

Current methodologies to assistance counteractive action What's more medicine of maternal prompted hypotension coming about because of spinal anesthesia, incorporate giving supplemental intravenous liquids toward the run through the spinal may be set Furthermore with the utilization of pressor operators ,as phenylepherine alternately ephedrine ,to wrist bindings hypotension accompanying spinal anesthesia [5].

An exploration examine need turned out that the same measurements from claiming nearby analgesic camwood be given should patients for an extensive
Contrast clinched alongside their stature for a dependable and reliable analgesic level attained [6].

It need ended up An act about large portions anesthesiologists should provide for an altered dosage about nearby analgesic should the sum patients in any case their stature [7].

A large number anaesthesiologists suggest fluctuating those measurement of neighborhood analgesic relying upon tolerant stature Toward their clinical experience [8].

Finding the best measurement of intrathecal nearby analgesic to patients for separate statures undergoing cs might oblige stricking those perfect gas parity between those often clashing requests from claiming keeping patients uneasiness same time Additionally avoiding unfriendly maternal impacts ,particularly hypotension and queasiness [9].

Intrathecal dosage prerequisite will be referred to to decline Throughout pregnancy. You quit offering on that one purpose behind this ,is the epidural venous engorgement coming about because of uterine expansion What's more ensuing venacaval layering ,displacing the CSF inside the subarachnoid space Furthermore making a diminishing in the prerequisite to intrathecal medication or a build Previously, its intrathecal spread [10].

The utilization of easier doses from claiming intrathecal neighborhood analgesic for spinal blockage may be energized with minimize post spinal unfriendly impacts Throughout cesarean conveyance [11].

\section{Subjects and methods}




\subsection{Ethics Committee}

This study was conducted on $\wedge$. patients aged between 20 and 40 years old, ASA grade I and II . All patients were scheduled for elective cesarean section surgery. All cases were done in Benha university Hospitals after approved consent from the patients. Type of Study: Prospective, comparative, double blind randomized clinical study.

\subsection{Inclusion Criteria}

1- ASA physical status classes I, II, 2- Age range between $20-40$ years, 3- Type of operation : elective cesarean section surgery and 4- Methods of randomization: Closed envelope.

\subsection{Exclusion Criteria}

Patient refusal, Parturients in labor, The patients with known history of allergy to amide local anesthetics or opioids, Extremes of height $(<140$ or $>185 \mathrm{~cm}$ ), Infection at site of the injection, Any preexisting neurological disease, Failed spinal anesthesia, Obstetric complications like placenta previa and multiple pregnancies, ASA physical status classes III or IV and Patients receiving any anti-coagulant.

\subsection{Group allocation:Patients were randomly allocated into four equal groups \\ 2.4.1 Group I}

Included 20 normal patients who were not suffering from any medical disease and received a fixed dose of bupivacaine that was $12.5 \mathrm{mg}$ of bupivacaine $0.5 \%$ $(2.5 \mathrm{ml})$.

\subsubsection{Group II}

included 20 normal patients who were not suffering from any medical disease and received variable doses of bupivacaine $0.5 \%$ according to patient's height.

\subsubsection{Group III}

Included 20 pre-eclamptic patients that received a fixed dose of bupivacaine that was $12.5 \mathrm{mg}$ of bupivacaine $0.5 \%(2.5 \mathrm{ml})$.

\subsubsection{Group IV}

will include 20 pre-eclamptic patients that received a variable doses of bupivacaine $0.5 \%$ according to patient height .

\subsection{Methodology}

\subsubsection{Anesthetic management}

All patients were evaluated initially by medical history and a complete physical examination, routine preoperative investigations were done (e.g CBC, PT, PTT, INR, liver function tests , kidney function tests and ECG) for evaluation of the patient medical status. No premedication was administered .Patients was admitted to the operating room fasting for $6 \mathrm{~h}$ at least. A peripheral i.v. $18 \mathrm{G}$ catheter was inserted and rapid intravenous infusion of saline $10 \mathrm{ml} / \mathrm{kg}$ over 15 minutes . Standard monitoring applied to the patients including continous electrocardiogram, pulse oximeter and non invasive blood pressure. Baseline blood pressure and maternal heart rate were recorded before lumbar puncture, recording continue at 1- minute intervals for the first 20 - minutes after spinal injection and then every 5 minutes till end of surgery.

I.V line was administered under complete aseptic conditions, all cases were injected in the sitting position, they were administered $3 \mathrm{ml}(60 \mathrm{mg}) 2 \%$ lidocaine infiltration anesthesia at level L3-L4 or L 4-5 after disinfected with antiseptic solution. Patients received intrathecal injection of the previous drugs according to each group over 15 seconds using a 23$25 \mathrm{G}$ spinal needle at the level intervertbral disk L3-L4 or L 4-5. After injection Patients were immediately turned supine and wedge position maintained to minimize aortocaval compression.

Block profile assessed at $2-$ min intervals for the first 20 minutes, thereafter the anesthesia onset time (time from end of injection of local anesthesia in subarachnoid to bilateral loss of pin - prick sensation at T6 level). Assessed in mid clavicular line using a 24 gauge sterile needle. During this period the following data was recorded : blood pressure, heart rate, oxygen saturation, respiratory rate, maximum sensory block level, time needed for maximum level to be reached, degree of motor block assessed by modified Bromage score $(0=$ no impairment, $1=$ unable to raise extended legs but able to move knees and ankles; $2=$ unable to extend legs or flex knees but able to move feet; $3=$ unable to flex ankles, knees or hips), and time taken to reach maximum Bromage score. Also the following data were recorded: duration of surgery, fetal extraction time (time between start of surgery till delivery of fetus), total dose of oxytocin administrated postdelivery, frequency of hypotension episodes, total amount of ephedrine, other complications also recorded as nausea, vomiting, , total volume of fluids infused and blood loss (estimated in graded suction bottle and observation of soaked materials).

Hypotention defined as SBP $<100 \mathrm{mmHg}$ or MBP decrease $>20 \%$ from baseline, treated with intravenous ephdedrine 5-10 mg boluses, bradycardia defined as heart rate $<50 \mathrm{bpm}$ and treated with intravenous atropine $0.6 \mathrm{mg}$.

Surgery via transverse lower abdominal incision was allowed to start once sensory block reach or exceed bilateral T6 sensory dermatomes. If this was not achieved after 10 minutes, the patient were positioned in the $10^{\circ}$ head down tilt to reach desirable block level T6. After delivery, patients were given 20 unit oxytocin in $500 \mathrm{ml}$ saline at rate 10 unit / $\mathrm{h}$ and uterine repair was performed by surgeon. If patients reported pain or discomfort during surgery as assessed by VAS $\geq 40$, bolus of intravenous fentanyl $1.5 \mathrm{ug} / \mathrm{kg}$ given (repeated once), if discomfort continue protocol allow for general anesthesia conversion.

Pain intensity was recorded during skin incision, uterus incision, and closure of peritoneam, postoperative $30 \mathrm{~min}$, and postoperative $60 \mathrm{~min}$ and when there is pain. In assessment of pain intensity, 10 $\mathrm{cm}$ visual analogue scale (VAS) is used. Before 
operation, VAS was explained to patients as; "0" no pain,"10"intolerable-pain

Postoperative, in PACU, haemodynamics and block profile monitoring were continued till sensory level regressed below L1 and patients can freely move lower limb.

\subsection{Statistical Analysis}

Data were analyzed by using SPSS version 21.

\section{Results}

All groups were similar in regard to age, weight, height and BMI with no significant differences between fixed dose groups (A\&C) and adjusted dose groups(B\&D) Fig (1)

On a dose adjustment for height, significantly ( $\mathrm{P}<$ 0.001) smaller amount of hyperbaric bupivacine, median IQR; 2.3 $\{1.8-2.7 \mathrm{ml}\}, 2.05(1.8-2.9 \mathrm{ml})$ were given intrathecally in adjusted dose group B and D respectively than given to fixed dose group patients $\mathrm{A}$ and C; $2.5 \mathrm{ml}$. This table shows Spinal anesthetic was placed L3-4 interspace in 25\% of patients in group A, $35 \%$ of patients in group B, $50 \%$ of patients in group C and $55 \%$ in group $\mathrm{D}$, with the reminder of patients received spinal anesthesia at L4-5 interspace Table (1).

The Time of the block to reach T6 level was significantly $(\mathrm{P}<0.001)$ prolonged in group $\mathrm{B}$ (adjusted dose) than in group A ( fixed dose) $(4.70 \pm 1.129$ vs $2.95 \pm 0.887 \mathrm{~min})(\mathrm{P}=0.000003)$. Also it was significantly prolonged in group $\mathrm{D}$ (adjusted dose) than in group $\mathrm{C}$ (fixed dose) $(3.80 \pm 0.768$ vs $3.35 \pm 0.489 \mathrm{~min}),(\mathrm{P}=0.033)$,. Table $(2)$.

Peak sensory level reachs T6 level in 2 patients in group A (fixed dose ) and 6 patients in group B (adjusted dose), reaches T4 level in 2 patients in group $\mathrm{A}$ and 9 patients in group $\mathrm{B}$ and the level was above T4 level in 16 patients in group A and 5 patients in group B Table (3)
The time for block to regress below L1 was significantly $(\mathrm{P}<0.001)$ prolonged in group A (fixed dose) than in group B (adjusted dose) (130.25 1 7. 518 vs $115.10 \pm 8.252 \mathrm{~min}$ ). Also,it was significantly ( $\mathrm{P}<$ $0.001)$ prolonged in group $\mathrm{C}$ (fixed dose) than in group $\mathrm{D}$ (adjusted dose) $(132.20 \pm 19.917$ vs $109.20 \pm 18.272$ min) Table (4).

Duration of sensory block was significantly ( $\mathrm{P}$ $<0.02$ ) prolonged in group A (fixed dose) than in group $\mathrm{B}$ (adjusted dose) $(164.52 \pm 12.533$ vs $154.33 \pm 8.342$ $\mathrm{min})$. it Also, it was significantly $(\mathrm{P}<0.04)$ prolonged in group $\mathrm{C}$ (fixed dose) than in group $\mathrm{D}$ (adjusted group) (172.75 $\pm 25.138 v s \quad 146.46 \pm 11.64 \mathrm{~min})$ Table (5).

Duration of motor block was significantly $(\mathrm{P}<$ 0.017 ) prolonged in group A (fixed dose) than in group B (adjusted dose) (134.25 \pm 10.422 vs $126.50 \pm 9.191 \mathrm{~min})$. Also, it was significantly prolonged ( $\mathrm{P}<0.001$ ) in group $\mathrm{C}$ (fixed group) than in group D (adjusted dose) $(141.75 \pm 19.076$ vs $118 \pm 12.814 \mathrm{~min})$ Table (6).

The dose of ephedrine used was significantly different $(\mathrm{P}<0.001)$ between group A (fixed dose) and group B (adjusted dose), $(25.125 \pm 14.7585 \mathrm{vs}$ $5.850 \pm 4.4665 \mathrm{~min})$. Also, it was significantly different $(\mathrm{P}<0.001)$ between group $\mathrm{C}$ (fixed dose) and group D (adjusted dose) (28.050 $\pm 11.2553 \mathrm{vs} \quad 5.150 \pm 5.5656 \mathrm{~min})$ More doses of ephedrine were needed in fixed groups (A \& C) than in adjusted groups (B \& D) Table (7).

Apgar scores of newborns was similar in group A (fixed dose) and B (adjusted dose), at 1 and 5 minutes interval, with no significant differences . Also,it was similar in group C (fixed dose) and D (adjusted dose), at 1 and 5 minutes interval, with no significant differences Table (8).

No significant differences were identified between the groups A (fixed group) and B (adjusted dose) or between group $\mathrm{C}$ (fixed group) and D (adjusted dose) regarding the urine output (UOP), estimated blood loss and duration of surgery Table (9).

Table (1) Total volume of injectant (ml) and Level of injection in studied groups

\begin{tabular}{|c|c|c|c|c|c|c|c|}
\hline & & Group A & Group B & $\begin{array}{c}p \text { - } \\
\text { value }\end{array}$ & Group C & Group D & $\begin{array}{c}p \text { - } \\
\text { value }\end{array}$ \\
\hline $\begin{array}{l}\text { Total volume } \\
\text { injectant (LA } \\
\text { dose) }(\mathrm{ml})\end{array}$ & & 2.5 & $\begin{array}{c}2.3\{1.8- \\
2.7\}\end{array}$ & $\begin{array}{c}<0.00 \\
1 * *\end{array}$ & 2.5 & $\begin{array}{c}2.05(1.8- \\
2.9)\end{array}$ & $\begin{array}{l}<0.00 \\
1 * *\end{array}$ \\
\hline \multirow{2}{*}{$\begin{array}{l}\text { Level of inject } \\
\text { Tion }\end{array}$} & $\begin{array}{l}\text { between } \\
\text { L3\&4 }\end{array}$ & $5(25 \%)$ & $7(35 \%)$ & \multirow[t]{2}{*}{.114} & $10(50 \%)$ & $11(55 \%)$ & \multirow[t]{2}{*}{.752} \\
\hline & L4\&5 & $15(75 \%)$ & $13(65 \%)$ & & $10(50 \%)$ & $9(45 \%)$ & \\
\hline
\end{tabular}

Table (2) Time (min) to reach T6 level (onset )

\begin{tabular}{|c|c|c|c|c|c|c|}
\hline & Group A & Group B & P-value & Group C & Group D & $\begin{array}{c}\text { P- } \\
\text { value }\end{array}$ \\
\hline $\begin{array}{l}\text { Time to } \\
\text { reach } \\
\text { T6(Onset) } \\
\text { (min) }\end{array}$ & $2.95 \pm 0.887$ & $4.70 \pm 1.129$ & $\begin{array}{c}.000003 \\
<0.001 * *\end{array}$ & $3.35 \pm 0.489$ & $3.80 \pm 0.768$ & $0.033 *$ \\
\hline
\end{tabular}




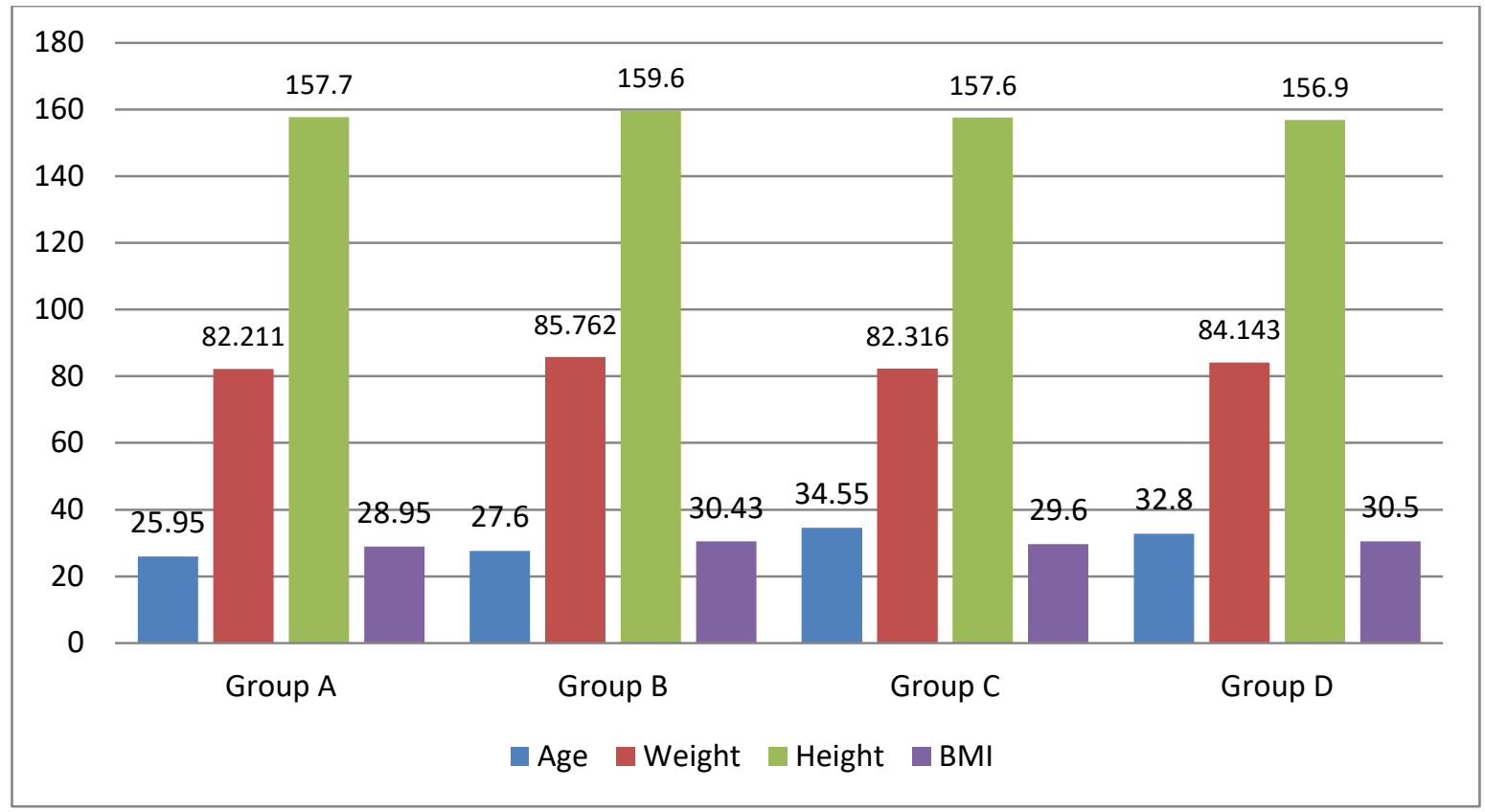

Fig (1) Mean of Demographic data of studied groups

Table (3) Peak sensory level in studied groups

\begin{tabular}{lccccccc}
\hline & & Group A & Group B & $p$-value & Group c & Group d & p- value \\
\hline $\begin{array}{l}\text { Peak } \\
\text { sensory } \\
\text { level }\end{array}$ & At T6 & $2(10 \%)$ & $6(30 \%)$ & & & & \\
& & & & & & & \\
& At T4 & $2(10 \%)$ & $9(45 \%)$ & & $6(30 \%)$ & \\
& $\begin{array}{l}\text { Above } \\
\text { T4 }\end{array}$ & $16(80 \%)$ & $5(25 \%)$ & & $13(65 \%)$ & $4(20 \%)$ & \\
\hline
\end{tabular}

Table (4) Time to regression below L1 (min) in studied groups

\begin{tabular}{lcccccc}
\hline & Group A & Group B & p- value & Group c & Group d & p- value \\
\hline $\begin{array}{l}\text { Time to } \\
\text { regressio }\end{array}$ & & & & & & \\
n below & $130.25 \pm 7.518$ & $115.10 \pm 8.252$ & .000 & & & \\
$\begin{array}{l}\text { L1. } \\
(\mathbf{m i n})\end{array}$ & & & $<0.001^{* *}$ & $132.20 \pm 19.917$ & $109.20 \pm 18.272$ & $<0.001 * *$ \\
\hline
\end{tabular}

Table (5) Duration of sensory block(min) in studied groups

\begin{tabular}{lcccccc}
\hline & Group A & Group B & $\begin{array}{c}p \text { - } \\
\text { value }\end{array}$ & Group c & Group d & $\begin{array}{c}p \text { - } \\
\text { value }\end{array}$ \\
\hline $\begin{array}{l}\text { Duration of } \\
\text { sensory block } \\
\text { (min) }\end{array}$ & $\begin{array}{c}164.52 \pm 12.5 \\
33\end{array}$ & $154.33 \pm 8.342$ & & $172.75 \pm 25.138$ & $146.46 \pm 11.64$ & $<0.04$ \\
\hline
\end{tabular}

Table (6) Duration of motor block (min) in studied groups

\begin{tabular}{lllllll}
\hline & Group A & Group B & $\begin{array}{l}\boldsymbol{p} \text { - } \\
\text { value }\end{array}$ & Group C & Group D & p- value \\
\hline $\begin{array}{l}\text { Duration } \\
\text { of motor } \\
\text { block } \\
\text { (min) }\end{array}$ & $134.25 \pm 10.422$ & $126.50 \pm 9.191$ & $<0.017 *$ & $141.75 \pm 19.076$ & $118 \pm 12.814$ & $<0.001 * *$ \\
\hline
\end{tabular}


Table (7) Total dose (mg) of vasopressors (ephedrine) used in studied groups

\begin{tabular}{|c|c|c|c|c|c|c|}
\hline & Group A & Group B & p-value & Group C & Group D & p-value \\
\hline $\begin{array}{l}\text { Dose of } \\
\text { ephedrine } \\
\text { (mg) }\end{array}$ & $\begin{array}{l}25.125 \pm 14.758 \\
5\end{array}$ & $5.850 \pm 4.4665$ & $.0001^{*}$ & $28.050 \pm 11.2553$ & $5.150 \pm 5.5656$ & $.0001 *$ \\
\hline
\end{tabular}

Table (8) APGAR score in studied groups

\begin{tabular}{lllllllll}
\hline $\begin{array}{l}\text { APGAR } \\
\text { score }\end{array}$ & Group A & Group B & Test & P-value & Group C & Group D & Test & P-value \\
\hline $\mathbf{1}$ min. & $7.16 \pm 0.624$ & $7.36 \pm 0.64$ & 1.12 & 0.26 & $7.24 \pm 0.72$ & $7.4 \pm 0.70$ & 0.79 & 0.43 \\
$\mathbf{5}$ min. & $9.36 \pm 0.49$ & $9.44 \pm 0.5$ & 0.56 & 0.57 & $9.4 \pm 0.5$ & $9.52 \pm 0.51$ & 0.84 & 0.4 \\
\hline
\end{tabular}

Table (9) UOP (ml), Estimated blood loss (ml) and duration of surgery (min) in studied groups

\begin{tabular}{lcccccc}
\hline & Group A & Group B & $\begin{array}{c}\text { p- } \\
\text { value }\end{array}$ & Group c & Group d & $\begin{array}{c}\text { p- } \\
\text { value }\end{array}$ \\
\hline $\begin{array}{l}\text { UOP } \\
(\mathbf{m l})\end{array}$ & $154.500 \pm 94.282$ & $\begin{array}{c}164.000 \pm 128.2 \\
534\end{array}$ & .791 & $\begin{array}{c}122.00 \pm \\
42.128\end{array}$ & $128.00 \pm 54.734$ & .700 \\
$\begin{array}{l}\text { Estimated blood } \\
\text { loss (ml) }\end{array}$ & $692.50 \pm 87.772$ & $725 \pm 75.219$ & 0.216 & $680 \pm 102.8$ & $710 \pm 127.37$ & 0.36 \\
$\begin{array}{l}\text { Duration of } \\
\text { surgery } \\
(\text { min) }\end{array}$ & $50.900 \pm 5.6559$ & $49.750 \pm 5.9549$ & .535 & $59.88 \pm 14.73$ & $53.52 \pm 13.87$ & 0.12 \\
\hline
\end{tabular}

\section{Discussion}

Late patterns for obstetric anesthesia show expanded Ubiquity for territorial anesthesia "around obstetric anaesthetists. General anesthesia will be connected with higher mortality in examination with territorial anesthesia. Territorial anesthesia need exactly risks; passings would principally identified with unreasonable helter skelter territorial obstructs and poisonous quality about nearby anesthetics. Decrease in doses Also change in procedure will dodge higher square levels and heightened mindfulness of the poisonous quality of nearby anesthetics have helped the decrease for difficulties related with territorial anesthesia [12]. Expansion about opioids should neighborhood anesthetics intrathecally potentiate surgical anesthesia, settling on the patients a greater amount fulfilled by their analgesic. Opioids have particular site for movement in spinal cord, synergistically it enhances 1 . An impact on efferent pathway without impact ahead thoughtful pathway so improve torment alleviation without haemodynamic changes [18]. To our study the sum patients required accepted intrathecal fentanyl over a measurement of 20 mcq on potentiate the piece. [13].

In the present study, eighty female patients were haphazardly allocated under four rise to bunches. Each bunch incorporates 20 patients. Assembly An : included 20 ordinary patients who were not enduring starting with any restorative malady and accepted an altered dosage about bupivacaine that might have been $12.5 \mathrm{mg}$ of bupivacaine $0.5 \%(2.5 \mathrm{ml})$. Gathering b : incorporated 20 typical patients who were not enduring from any medicinal ailment What's more gained variable doses of bupivacaine $0.5 \%$ as stated by patient's tallness. One assembly c's : incorporated 20 pre-eclamptic patients that accepted an altered dosage about bupivacaine that might have been $12.5 \mathrm{mg}$ about bupivacaine $0.5 \%(2.5 \mathrm{ml})$. Assembly d : incorporated 20 pre-eclamptic patients that accepted variable doses of bupivacaine $0.5 \%$ as stated by tolerant tallness. Every one patients On the whole bunches gained a dosage for 20 microgram about fentanyl.

Our examine will be will alter dosage from claiming intrathecal neighborhood analgesic to elective cesarean area as stated by stature utilizing focuses from claiming bupivacaine regularly utilized Previously, clinical act in both typical Also pre-eclamptic tolerant. Those point of the study will get best offset between sufficient absense of pain and the require on diminish measurement with Abstain from maternal What's more fetal unfriendly impacts.

Those measurement change about intrathecal bupivacine $(0.5 \%)$ might have been completed as stated by table 1 altered starting with neighborhood anesthetics regularly utilized for cesarean area for subarachnoid square table from claiming [14].

Similarly as respects of the occasion when for onset about engine barricade ( $\mathrm{min}$ ) and the span about it (min); the the long haul from claiming engine square with achieve T6 level might have been altogether $(\mathrm{P}<$ 0 . 001) prolonged for balanced measurement Assemblies (B\&D) over On altered measurement aggregations (A\&C). Same time the span about engine piece might have been fundamentally shorter to balanced measurements Assemblies (B\&D) over to settled dosage bunches (A\&C). These effects were in 
understanding for the consider carried out by [15] , who committed An similar examine the middle of settled measurement for intrathecal hyperbaric bupivacaine $0.5 \%$ What's more stature balanced measurements from claiming intrathecal hyperbaric bupivacaine $0.5 \%$ Throughout cesarean segment Furthermore found that one assembly FD (Fixed dose) might have been with sooner onset Furthermore All the more prolonged span of engine piece over for balanced measurements gathering as stated by tallness.

As views should period to greatest Bromage scale; those the long run on achieve most extreme Bromage scale might have been altogether prolonged clinched alongside balanced measurement Assemblies (B\&D) over Previously, altered dosage Assemblies (A\&C). This is in understanding for those ponder for [16] who needed An investigation once two bunches for patients undergoing cesarean section,the primary gathering gained an altered measurements for intrathecal bupivacaine $0.5 \%$ and the different assembly accepted an balanced measurements from claiming intrathecal bupivacaine $0.5 \%$ as stated by stature. They found that the the long haul should scope greatest Bromage scale might have been that's only the tip of the iceberg prolonged to balanced measurements aggregation over in the other one assembly.

As respects of the necessity to vasopressors (ephedrine) ; The occurrence of the necessity to vasopressors might have been markedly higher Previously, altered measurements bunches (group An What's more C) over over balanced measurement Assemblies (group b What's more one assembly D). Best 7 patients On altered measurements aggregations didn't have the utilization about ephedrine (17. 5\%) same time 30 patients to balanced dosage gatherings didn't necessity the utilization of vasopressors $(75 \%)$. There might have been change of maternal haemodynamics Previously, balanced measurement aggregations over settled measurements Assemblies reflected by stamped decline in the require for vasopressors. The current investigation matches for contemplate carried Toward [17]. 120 patients booked for elective cesarean segment under spinal anesthesia were incorporated. Those patients were isolated under two aggregations; settled measurements aggregation (FD group) accepted altered dosage about intrathecal 0 . $5 \%$ hyperbaric bupivacaine and the other one assembly accepted variable doses as stated by stature. They discovered that hyperbaric bupivacaine $(0.5 \%)$ dosing regimen dependent upon patient's stature attained sufficient anesthesia to cesarean segments with decreased utilization of vasopressors over done altered dosage one assembly.

Similarly as views to neonatal apgar score; develop placenta will be a profoundly capacitance organ with no autoregulation also others uteroplacental stream may be subject to systemic pulse. In spite of the fact that those occurrence What's more seriousness for maternal hypotention were diminished clinched alongside balanced dosage aggregations (group B\&C), we could not substantiate At whatever distinction for fetal result utilizing apgar score during 1 Furthermore 5 minutes which will be particular $\mathrm{Be}$ that not very delicate test. Future investigations measuring umbilical blood gasses and uteroplacental blood stream might substantiate that. Those current consider matches for consider finished by [18]. One hundred patients booked for elective cesarean segment under spinal anesthesia were included.

Those patients were isolated under two Assemblies. Altered dosage one assembly gained intrathecal 10mg for $0.5 \%$ hyperbaric bupivacaine and the balanced dosage bunch accepted stature based doses of intrathecal infusion about $0.5 \%$ hyperbaric bupivacaine. Neonatal result utilizing apgar score toward 1 Also 5 mins were noted. They found that there might have been no contrasts the middle of those two aggregations in regards neonatal result.

Same time utilizing for altered dosage for bupivacaine $0.5 \%(2.5 \mathrm{ml})$ over An tall tolerant About needed the same impacts as the utilization of the balanced measurement of bupivacaine $0.5 \%$ as stated by stature viewing those decline to frequency Furthermore seriousness for maternal hypotention ,nausea Also vomiting, diminish the measure of liquids required and those measurement from claiming vasopressors utilized. Also that's on those volume of the injectant not extending helter skelter bringing about no helter skelter thoughtful square.

\section{Conclusion}

We have indicated that changing the measurements for hyperbaric bupivacine $(0.5 \%)$ as stated by tallness done both typical What's more pre-eclamptic patients, On consolidation with opioids (fentanyl $20 \mathrm{mcq}$ ), give satisfactory anesthesia to elective cesarean area over both ordinary and pre-eclamptic patients. This regimen connected with diminish clinched alongside cephalic spread from claiming anesthesia, decline occurrence What's more seriousness of maternal hypotention ,nausea ,vomiting, diminishing the measure about liquids required and the measurement for vasopressors utilized.

\section{References}

[1] NM. Green , BC. Corke, ST. Datta, GW. Ostheimer, JB. Weiss, MH. Alper () : Spinal anaesthesia for Caesarean section. The influence of hypotension on neonatal outcome. Anaesthesia, Vol. 37, PP. 658-665, 1998.

[2] MC. Norris and YT. Ginosar, () : International journal of obstetric anesthesia, Vol. 21, PP. $207-$ 211, 2012.

[3] PM. Pan, ZF. Lin , JT. Lim, MC. Tung and TT. Weii () : The optimal dose of hyperbaric bupivacaine for spinal anesthesia for caesarean section ,Anesth Sinica, Vol. 27, PP. 349-352, 2000.

[4] CA. Simone, BL. Leighton and MC. Norris, () : Spinal anesthesia for caesarean delivery .Regional anesthesia, Vol. 20, PP. 90-94, 2002. 
[5] SM. Shnider and GD. Levison, () :.Anesthesia for obstetrics .Baltimore ,MD : Williams \& Wilkins, Vol. 79, PP. 2109-2113, 1998.

[6] AF. Santos, HD. Pedersen, MR. Finster and HW. Edstrom, () : Hyperbaric bupivacaine for spinal anesthesia for cesarean section. Anesth Analg, Vol. 63, PP. 1009-1013, 2011.

[7] KW. Ngan, () : Prevention of maternal hypotension after regional anesthesia for cesarean section .Curr Opin Anesthesiol, Vol. 23, PP. 304-309, 2010.

[8] JK. Hocking, and BT. Wildsmith, () : administration of intrathecal fentanyl better enhances the spread of spinal anaesthesia , Comp ClinPathol, Vol. 19, PP. 571-574, 2004.

[9] MK. Karmakar, TR. Gin and JF. Hoam, () : Spread of local anesthetic within subarachnoid space during cesarean section .Br J Anaesth, Vol. 87, PP. 312-326, 2007.

[10] RL. Gaiser, () : Physiologic changes in pregnancy .In: Chestnut DH , Polley LS , Tsen LC , Wong $\mathrm{CA}$,eds.Chestnut 's Obstetric Anesthesia principles and practice $.4^{\text {th }}$ ed .Philadelphia ,PA .Mosby Elsevier, Vol. 84, PP. 135-146, 2009.

[11] KJ. Grzegor, TY. Jagla, JE. Walocha and KF. Rajda () : Anatomical aspects of epidural and spinal anesthesia ,Adv. Pall .Med, Vol. 28, PP. 340-352, 2009.

[12] MG . Albright, CA. Reese, UI. Munnur and SS. Suresh () : Clinical Techniques of Regional Anesthesia. Anesthesia and Analgesia, Vol. 98, PP. 1426-1431, 2006.
[13] BV. David, AS. Rodgers, NW. Walker and SJ. Schug () : Reduction of postoperative mortality and morbidity with epidural or spinal anesthesia. Results from overview of randomized trials. British Medical Journal, Vol. 321, PP. 1493-1505, 2000.

[14] JM. Barash, DS. Graham and IF. Russell (): A double-blind assessment of the analgesic sparing effect of intrathecal fentanyl with spinal anaesthesia for elective caesarean section. Int $\mathbf{J}$ ObstetAnesth, Vol. 7, PP. 222-225, 2006.

[15] QL. Ruynat, RL. Carpenter, QH. Hogan and SS Liu () : Dose of intrathecal plain bupivacaine $0.5 \%$ is the primary determinant of sensory block extent and duration during spinal anesthesia. Anesthesiology, Vol. 89, PP. 24-29, 2012.

[16] MJ. Bergeron, CA. Wong, BM. Scavone, MC. Loffredi, WY. Wang, AM Peaceman, et al., (): The dose-response of intrathecal fentanyl added to bupivacaine for labor analgesia. Anesthesiology, Vol. 92, PP. 1553-1561, 2001.

[17] JH. Weinberg, (2008) : Cardiovascular collapse treated with intralipid. Anesthesia, Vol. 62, PP. 516-518.

[18] JL. George, YM. Ginosar, ET. Mirikatani, DR. Drover () : ED50 and ED95 of intrathecal hyperbaric bupivacaine coadministered with opioids for cesarean delivery. Anesthesiology, Vol. 100, PP. 676-682, 2017. 